\title{
Behavioral Modeling and Simulation with Experimental Analysis of a Two Stroke Engine Using Nanosized Copper Coated Catalytic Converter
}

\author{
Mukesh Thakur $^{1}$ and N. K. Saikhedkar ${ }^{2}$ \\ ${ }^{1}$ Reader, Department of Mechanical Engineering, \\ Rungta College of Engineering \& Technology, \\ Raipur (C.G.), India \\ ${ }^{2}$ Director and Professor, Department of Mechanical Engineering, \\ Raipur Institute of Technology, \\ Raipur (C.G.), India \\ ${ }^{1}$ mukeshrit77@rediffmail.com, ${ }^{2}$ nksaikhedkar1@gmail.com
}

\begin{abstract}
The Automobile pollution is the major source of pollution. The majority of the environmental pollution is from the two-wheeler automobiles due to their large number. A study on nano-particle reveals that the ratio of surface area of nano-particle to the volume of the nano-particle is inversely proportional to the radius of the nano-particle. So, on decreasing the radius, this ratio is increased leading to an increased rate of reaction and the concentration of the pollutants is decreased. To achieve this objective, an innovative design of catalytic converter for two-wheeler automobiles is proposed using nano-particle as a catalyst. This research paper basically deals with the behavioral modeling and simulation of two stroke engine with developed catalytic convertor. The basic idea of behavioral modeling starts from analyzing the practical behavior of two stroke engine with designed catalytic convertor, and then approximating obtained behavior in terms of mathematical equations. These obtained equations actually represent behavior of concern system. Once mathematical equations are obtained, next stage is to implementation of these equations in Simulink platform. The last process is the validation check by the simulation of developed model.
\end{abstract}

Keywords: Automobiles; catalytic converter; modeling; nano-particle; simulation

\section{Introduction}

Nanotechnology is one of the most emerging fields of science today due to its manifold applications and utility. Nano-particles are used for a variety of purposes from medical to scientific. Actually, when the size of a particle is reduced to the extent of about $10^{-9} \mathrm{~m}$, it is called nano-particle. The small size of the particle makes it highly reactive Therefore; the nano-particles are also used to treat a variety of ailments and diseases like cancer. The major contributor of environmental pollution is the exhaust emissions from the tail pipe of automobiles. A complete re-design may not be as lucrative as the modification of the exhaust tailpipe arrangement. The exhaust emissions can be treated by nano-particles before ejecting them to atmosphere [1]. The exhaust emissions mainly contain carbon di-oxide which causes global warming and CO which is very harmful to human health and welfare [2]. Unburnt hydrocarbons are present in exhaust emission due to incomplete combustion. The level of unburned hydrocarbons is 
specified as parts per million (ppm) carbon atoms. The total hydrocarbon emissions are used as a measure of the combustion efficiency. Treatment of the exhaust gas means that some cleaning action must occur after the exhaust emissions leave the engine cylinder and exit from the tail pipe which enters in to atmosphere [3]. A comprehensive review on the application of nano-technology in automotive pollution control was covered. First, the essential aspects of environmental problems due to automotive industry were discussed and then the application of nanotechnology towards the prevention and control of these problems were suggested in detail [4]. The utility of the nano-particles towards automobile pollution control was explained in detail. The nanoparticle coating on the catalytic converter of automobiles can be very helpful in the reduction of pollutant concentration and thus reduce the pollution level in atmosphere [5]. Amongst main metals like Au, Ag, Pd, Pt, towards which nanotechnology research is directed, copper and copper based compounds are the most important. The metallic Copper plays a significant role in modern electronics circuits due to its excellent electrical conductivity and low cost nanoparticles [6]. Copper based nano-particles are gaining wide popularity due to high reactivity and good conductivity [7]. The post pollution control method in two-wheeler automobiles using nano-particle as a catalyst was proposed. A study on nano-particle reveals that the ratio of surface area of nanoparticle to the volume of the nano-particle is inversely proportional to the radius of the nano-particle. So, on decreasing the radius, this ratio is increased leading to an increased rate of reaction and the concentration of the pollutants is decreased [8]. It involves the use of copper nano-particle which is cheaper than the platinum, palladium and rhodium nano-particles used in automobiles [9]. A microprocessor based analyzer was used for measurement of $\mathrm{CO}$ and $\mathrm{HC}$ emissions [10]. To control the exhaust emissions from two stroke single cylinder spark ignition petrol engine having copper nano-particles coated on copper sieve as catalytic converter was used. AVL-422 Gas analyzer was used for the measurement and comparison for $\mathrm{CO}$ and unburned hydrocarbon in the exhaust of the engine at various speeds and loads [11]. The conversion efficiency of a catalytic converter mounted on a vehicle with spark ignition engine was evaluated under steady operating conditions [12]. Three way converters have been compared to understand the influence of the substrate on the exhaust gas conversions for different operating conditions of vehicle [13]. Various tests conducted on four stroke engine reveal that the copper coated engine showed a better performance than a normal engine [14]. On using copper powder, the catalytic efficiency was found to increase as the size of the powder decreased [15]. A nano catalytic converter was designed and manufactured to reduce the pollution in the environment [16]. Nanocoatings can be used to reduce surface roughness of engine components and to act as protective coating against wear of components. Experiments were conducted to improve the engine performance and reduce the emissions of $\mathrm{HC}$ and $\mathrm{CO}$ from vehicle. Some alterations and modifications have been designed so as to increase the retention period of exhaust gases to provide more time for its oxidation and thereby to reduce harmful emissions [17]. The Experimental Setup is as shown in Figure 1: 


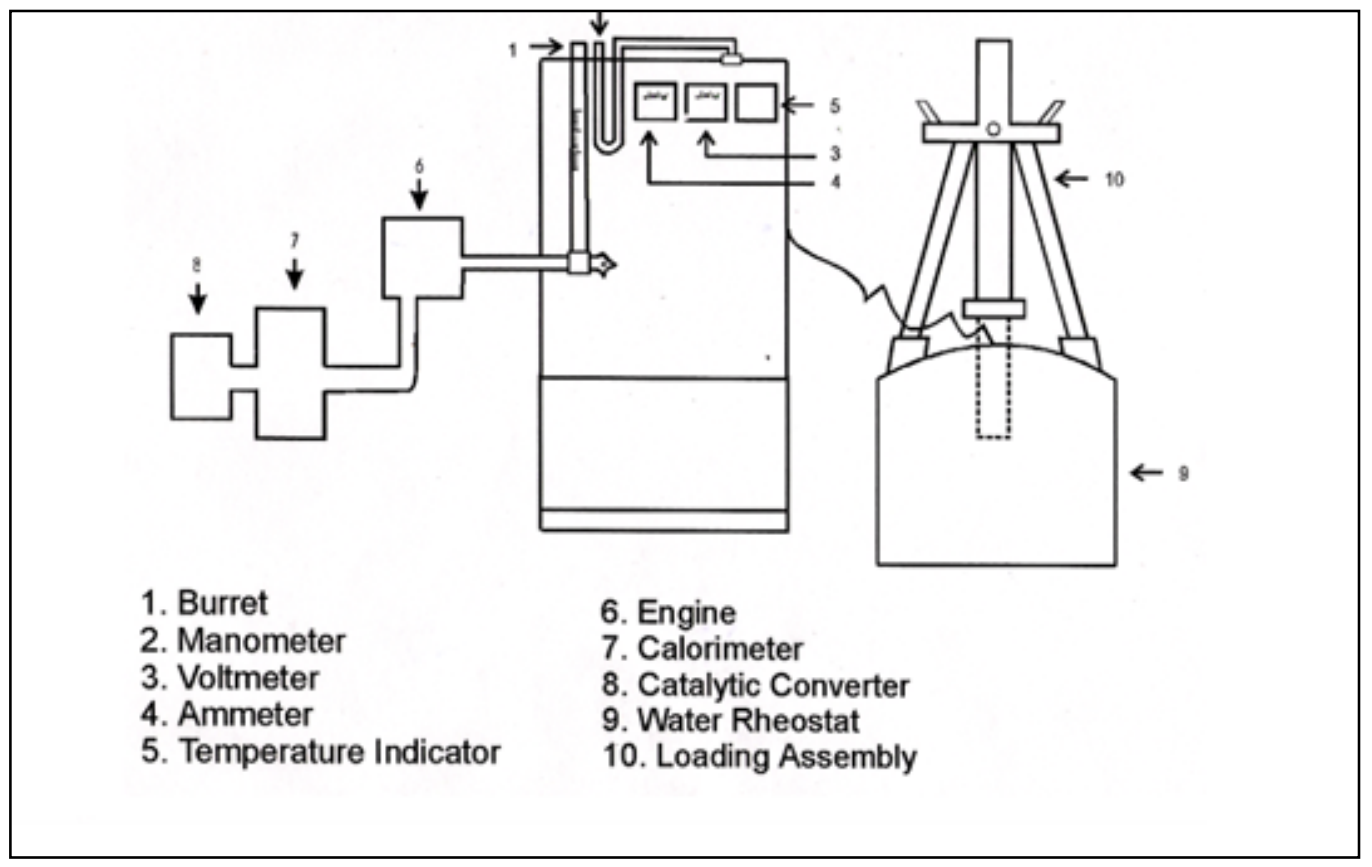

Figure 1. Experimental Setup

This research paper basically deals with the behavioral modeling and simulation of two stroke engine with developed catalytic convertor.

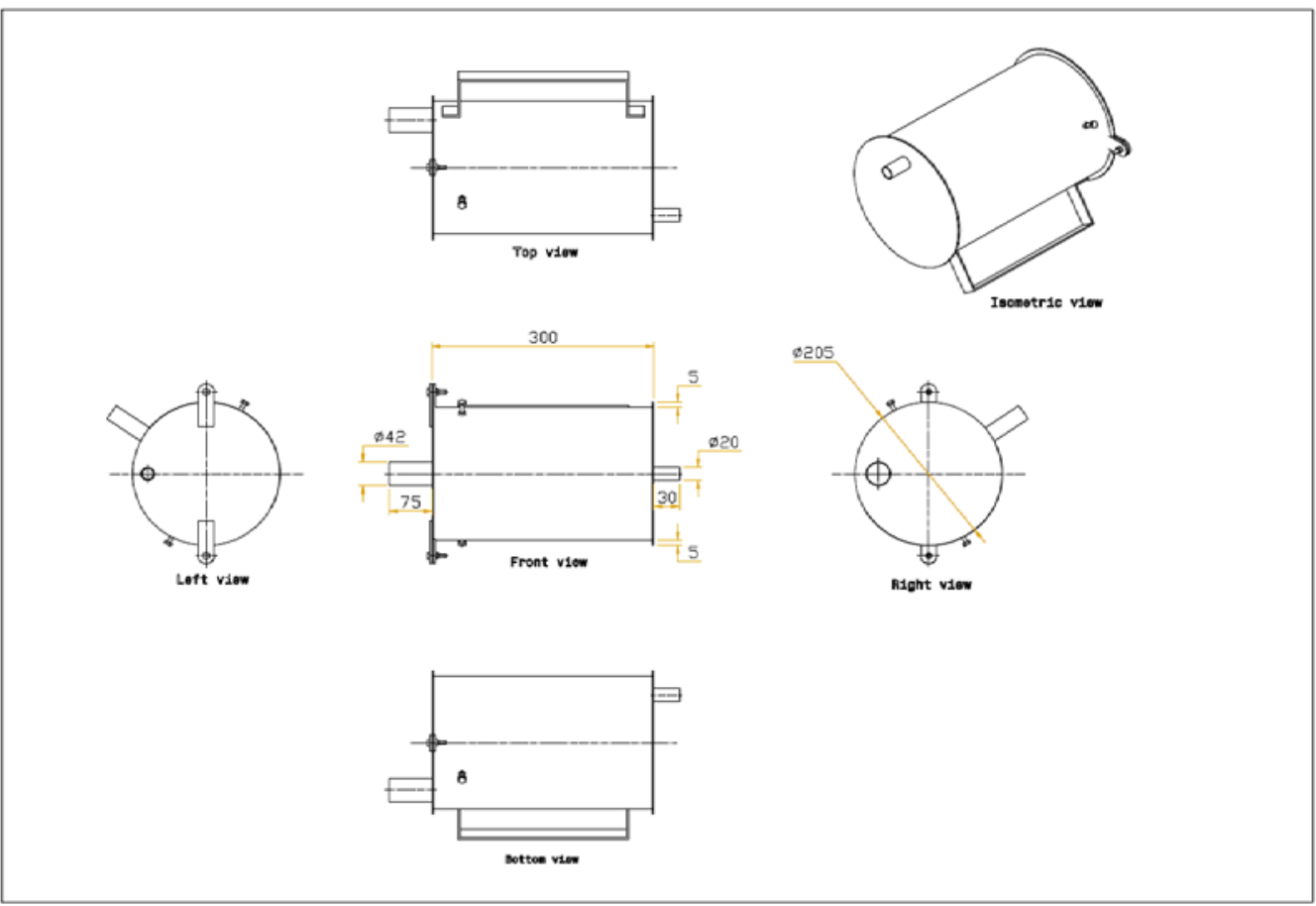

Figure 2 Different Three Dimensional Views of a Catalytic Converter 


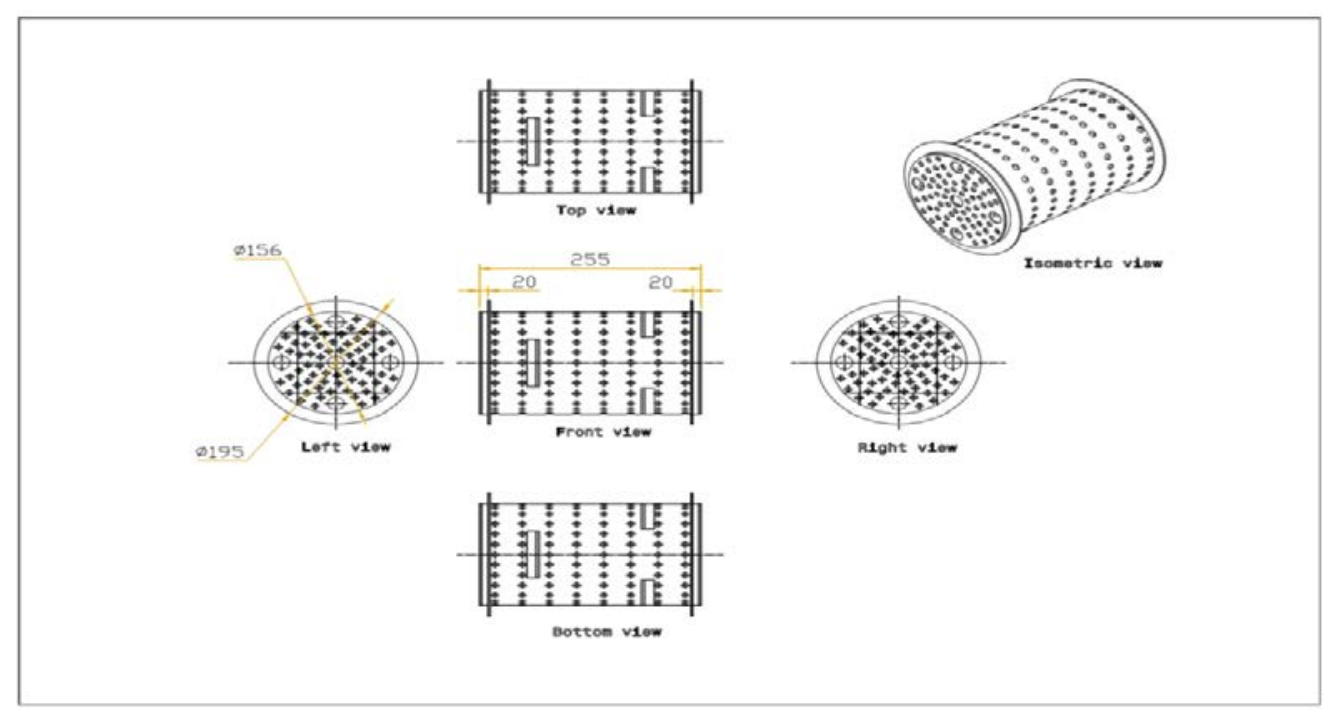

Figure 3. Cut Section Model of Designed Catalytic Converter

\section{Behavioral Modeling and Simulation of Two Stroke Engine and Designed Catalytic Convertor}

In behavioral science, system theory and dynamic system modeling, a behavioral model reproduces the required behavior of the original analyzed system, such as there is a one-to-one correspondence between the behavior of the original system and the simulated system. The behavioral approach is motivated by the aim of obtaining a framework for system analysis that respects the underlying physics. The behavior may be achieved in simulation with a mixture of ideal or otherwise physically unrealistic components if it successfully recapitulates the behavior of the system under analysis.

This section basically deals with the behavioral modeling and simulation of two stroke engine with developed catalytic convertor. The basic idea of behavioral modeling starts from analyzing the practical behavior of two stroke engine and designed catalytic convertor and then approximating obtained behavior in terms of mathematical equations. These obtained equations actually represent behavior of concern system. Once mathematical equations are obtained, next stage is to implementation of these equations in Simulink platform. The last process is the validation check by the simulation of developed model.

\subsection{Behavioral Modeling of Two Stroke Engine}

This subsection presents the complete behavioral modeling of two stroke engine, during modeling of engine following parameters are important and has to address during modeling.

i. Horse power of engine.

ii. Speed of engine in RPM.

iii. Applicable load during running condition.

These three important parameters are basically independent variable for modeling, and it is difficult to address simultaneously. However among these three, one can be assume constant, so for modeling of two stroke engine, in this paper horse power of 
engine is taken as constant, this leads the reduction of one independent variable from the list.

Now following steps provide complete idea of behavioral modeling of two stroke engine.

Step 1. Define the behavior of two stroke engine in terms of input and output variables. For modeling of this paper the input variables are:

i. Speed of engine in RPM.

ii. Applicable load during running condition.

Similarly the output variables for our work are

i. $\mathrm{CO}$ in percentage.

ii. $\mathrm{HC}$ in PPM.

To analyze the behavior of two stroke engine, practical experiment has been performed and data collected is shown in Table (1).

Table 1

\begin{tabular}{|c|c|c|c|}
\hline Speed In RPM & Load & COWCC in \% & HCWOCC in PPM \\
\hline \multirow{4}{*}{1500} & 0.25 & 1.5 & 1750 \\
\hline & 0.5 & 1.2 & 1650 \\
\hline & 0.75 & 1.3 & 1700 \\
\hline & 1 & 1.6 & 1800 \\
\hline \multirow{4}{*}{1800} & 0.25 & 1.2 & 1600 \\
\hline & 0.5 & 1 & 1550 \\
\hline & 0.75 & 1.1 & 1575 \\
\hline & 1 & 1.3 & 1700 \\
\hline \multirow{4}{*}{2000} & 0.25 & 1.16 & 1500 \\
\hline & 0.5 & 0.8 & 1350 \\
\hline & 0.75 & 0.9 & 1400 \\
\hline & 1 & 1.2 & 1600 \\
\hline \multirow{4}{*}{2200} & 0.25 & 1.6 & 1800 \\
\hline & 0.5 & 1.4 & 1600 \\
\hline & 0.75 & 1.5 & 1680 \\
\hline & 1 & 1.6 & 1720 \\
\hline
\end{tabular}

Step 2. From Table (1), it is clear that there are two different speed conditions and each speed value consist two different load conditions. So for proper behavioral analysis of two stroke engine, we have to analyze the complete behavior in two parts, 
i.e., based on different speed conditions. Hence the complete modeling is also divided in two parts.

Step 3. Modeling of two stroke engine for speed $=1500$ RPM. Table (2) shows the behavior of engine for 1500 RPM.

Table 2

\begin{tabular}{|l|l|l|l|}
\hline \multirow{3}{*}{ Speed In RPM } & Load & COWOCC in \% & HCWOCC in PPM \\
\hline \multirow{3}{*}{1500} & 0.25 & 1.5 & 1750 \\
\cline { 2 - 4 } & 0.5 & 1.2 & 1650 \\
\cline { 2 - 4 } & 0.75 & 1.3 & 1700 \\
\cline { 2 - 4 } & 1 & 1.6 & 1800 \\
\hline
\end{tabular}

Now by dividing the modeling in two parts actually provides reduction of second independent variable, and hence for modeling now we have only one independent variable and two dependent output variables. Figures (1) and (2) shows plot of CO and $\mathrm{HC}$ with respect to Load values for fixed speed $1500 \mathrm{rpm}$.

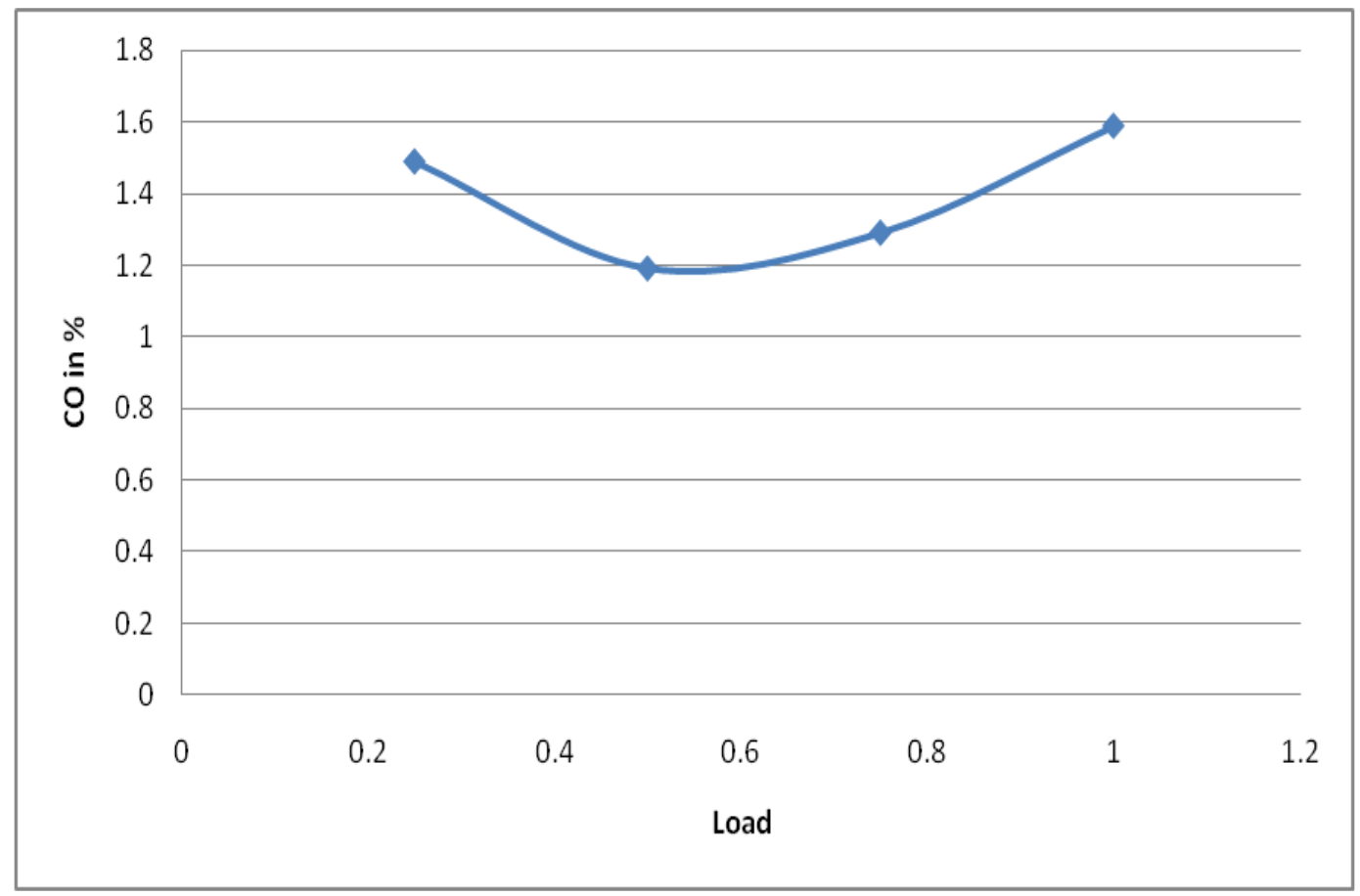

Figure 4. Load versus CO Graph 


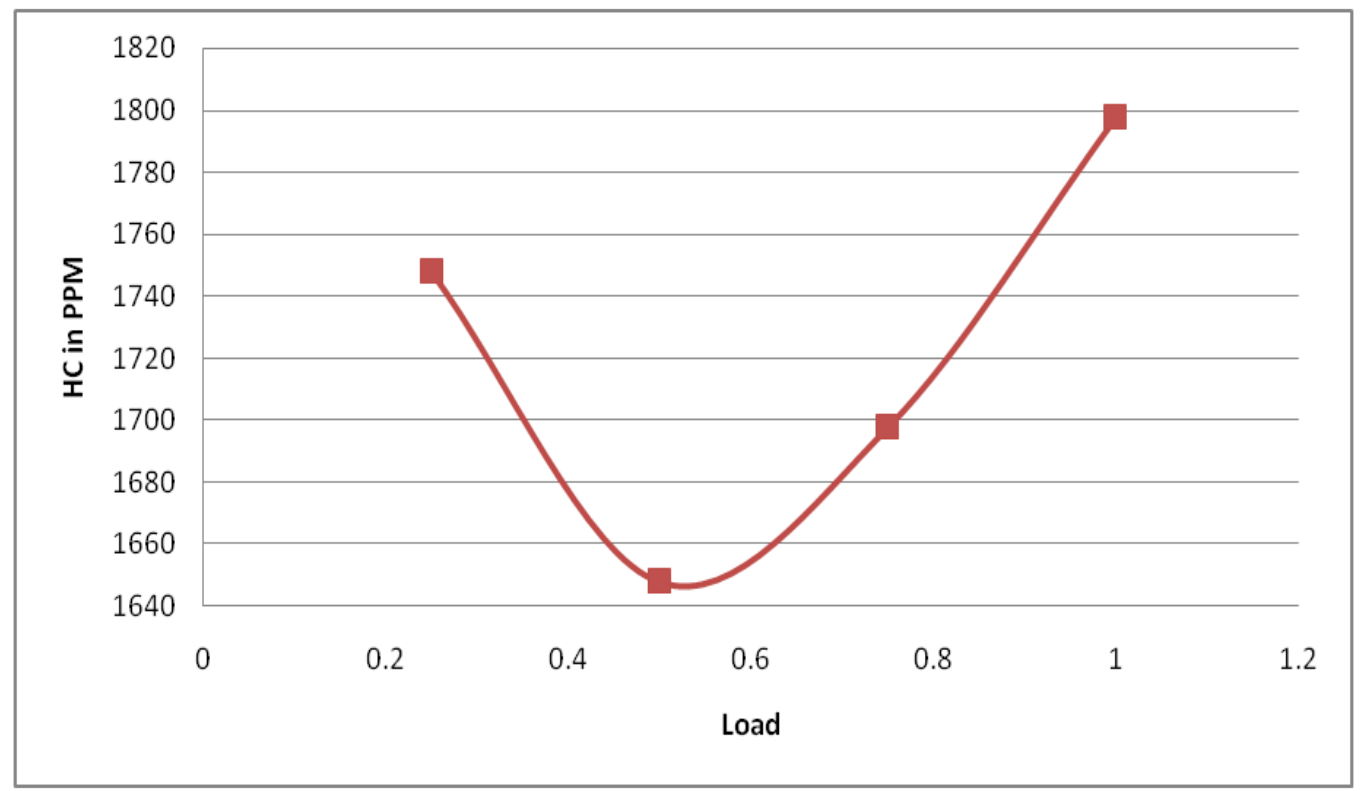

Figure 5. Load versus HC Graph

After using above figures, mathematical equations for $\mathrm{CO}$ and $\mathrm{HC}$ can be obtained as

$$
\begin{aligned}
& C O=-2.1333 x^{3}+6.4 x^{2}-5.066 x+2.39 \\
& H C=-1066 x^{3}+2800 x^{2}-2033 x+2098
\end{aligned}
$$

Step4. Modeling of equation 1 and 2 in MATLAB Simulink:

After getting the equations the next step is to make Simulink model.

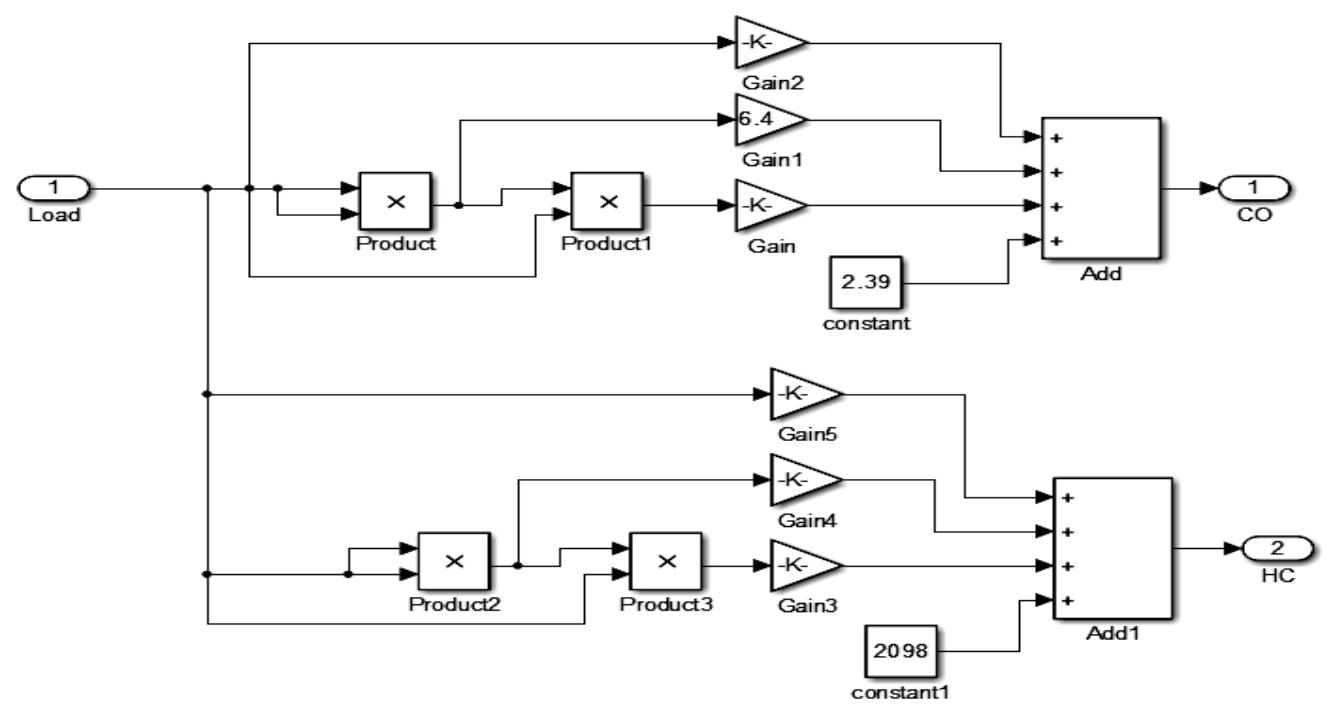

Figure 6. Actual Simulation Model of Two Stroke Engine for 1500 rpm

Step5. Similarly we can obtain equations for CO and HC for speed of 1800, 2000 and $2200 \mathrm{rpm}$. 
The equations obtained are as follows:

i. $\quad$ For Speed $=1800 \mathrm{rpm}$.

$C O=-2.1333 x^{3}+5.6 x^{2}-4.066 x+1.89$

$H C=266.6 x^{3}+200 x^{2}-466.6 x+1698$

ii. $\quad$ For Speed $=2000 \mathrm{rpm}$.

$$
\begin{aligned}
& C O=-2.773 x^{3}+7.84 x^{2}-6.106 x+2.23 \\
& H C=-533.3 x^{3}+2400 x^{2}-2166 x+1898
\end{aligned}
$$

iii. $\quad$ For Speed $=2200 \mathrm{rpm}$.

$$
\begin{aligned}
& C O=-4.266+9.6 x^{2}-6.533 x+2.79 \\
& H C=-2517 x^{3}+5792 x^{2}-4042 x+2486
\end{aligned}
$$

Step 6. Development of complete model including two models

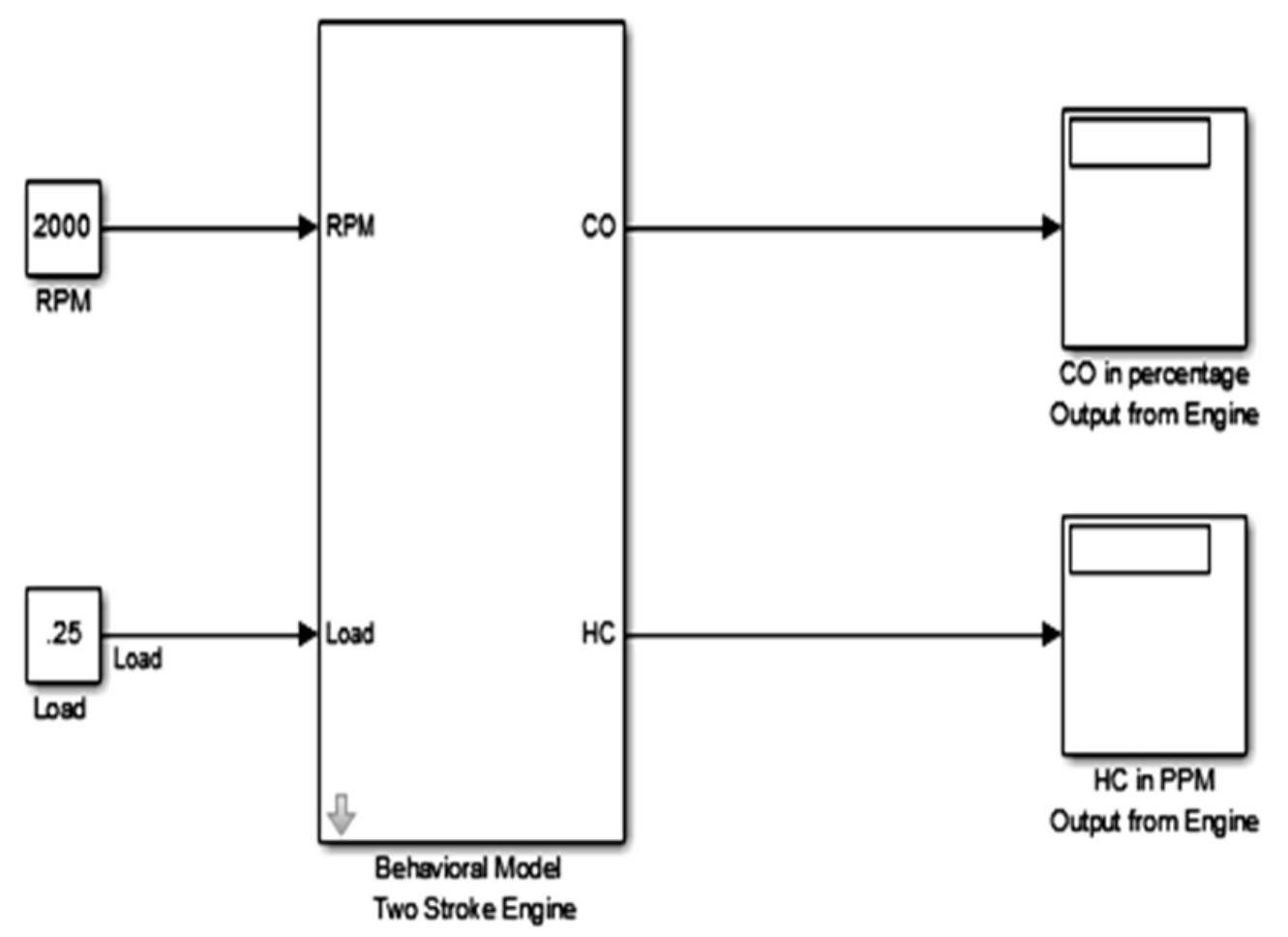

Figure 7. Complete Model of Two Stroke Engine

\subsection{Behavioral Modeling of Catalytic Convertor for Two Stroke Engine}

In this subsection we provide behavioral modeling of physically designed catalytic convertor for getting reduction in amount of $\mathrm{CO}$ and $\mathrm{HC}$ obtained from two stroke engine with the help of nano material. 
Step 1. Behavior analysis: Tables (3) and table (4), shows the practical behavior of physically designed catalytic convertor. Figures (5) and (6) shows corresponding plots.

Table 3

\begin{tabular}{|c|c|}
\hline CO IN \% & COWCC IN \% \\
\hline 0.8 & .4 \\
\hline 0.9 & .42 \\
\hline 1 & .4 \\
\hline 1.1 & .48 \\
\hline 1.16 & .45 \\
\hline 1.20 & .5 \\
\hline 1.3 & .55 \\
\hline 1.4 & .6 \\
\hline 1.5 & .6 \\
\hline 1.6 & .7 \\
\hline 1.7 & .8 \\
\hline
\end{tabular}

Table 4

\begin{tabular}{|c|c|}
\hline HC in PPM & HCWCC in PPM \\
\hline 1350 & 650 \\
\hline 1400 & 700 \\
\hline 1500 & 800 \\
\hline 1550 & 800 \\
\hline 1575 & 950 \\
\hline 1600 & 1000 \\
\hline 1650 & 1100 \\
\hline 1680 & 1200 \\
\hline 1700 & 1100 \\
\hline 1720 & 1350 \\
\hline 1750 & 1200 \\
\hline 1800 & 1250 \\
\hline
\end{tabular}


International Journal of Advanced Science and Technology Vol.59, (2013)

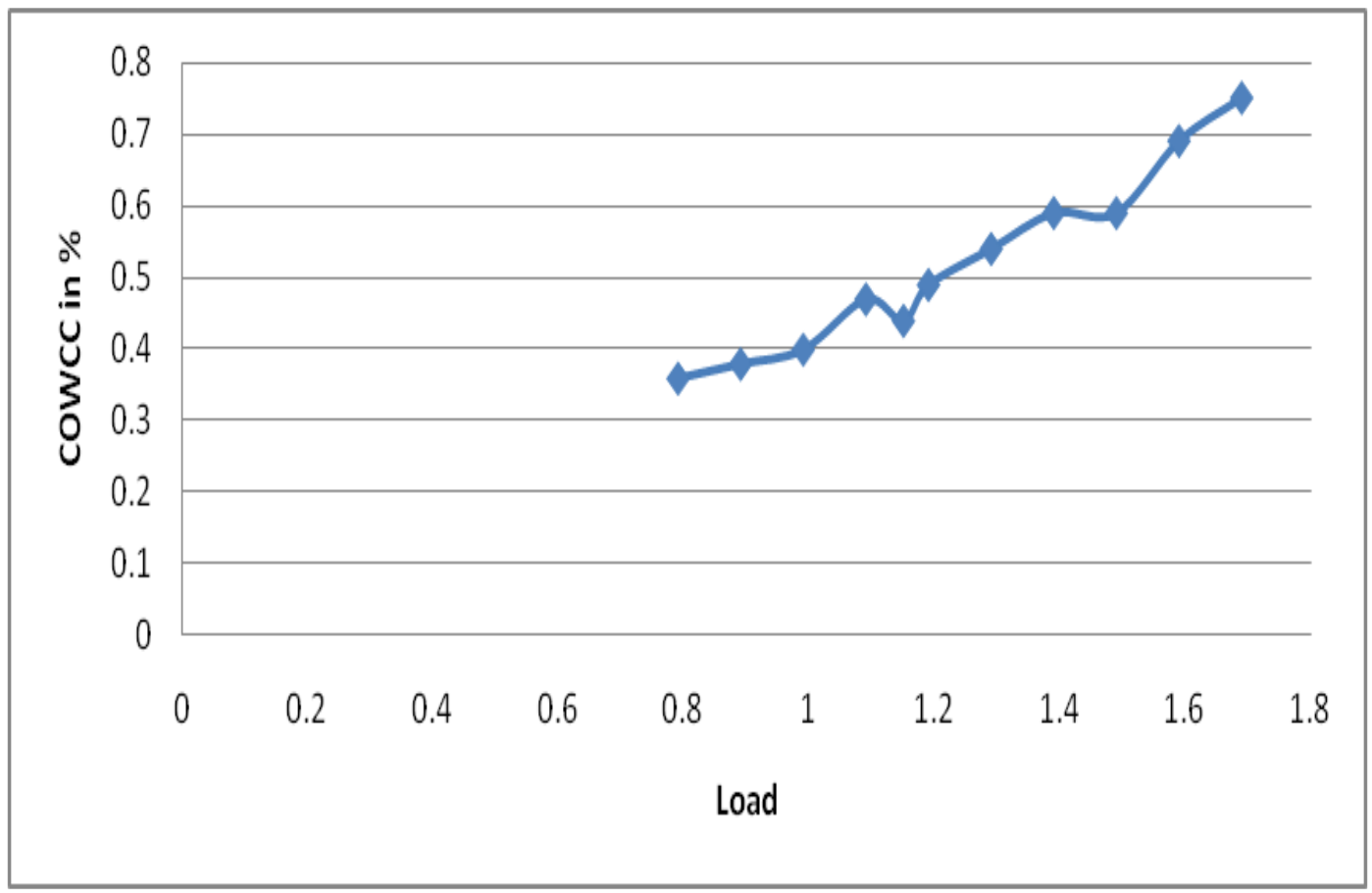

Figure 8. Load versus COWCC

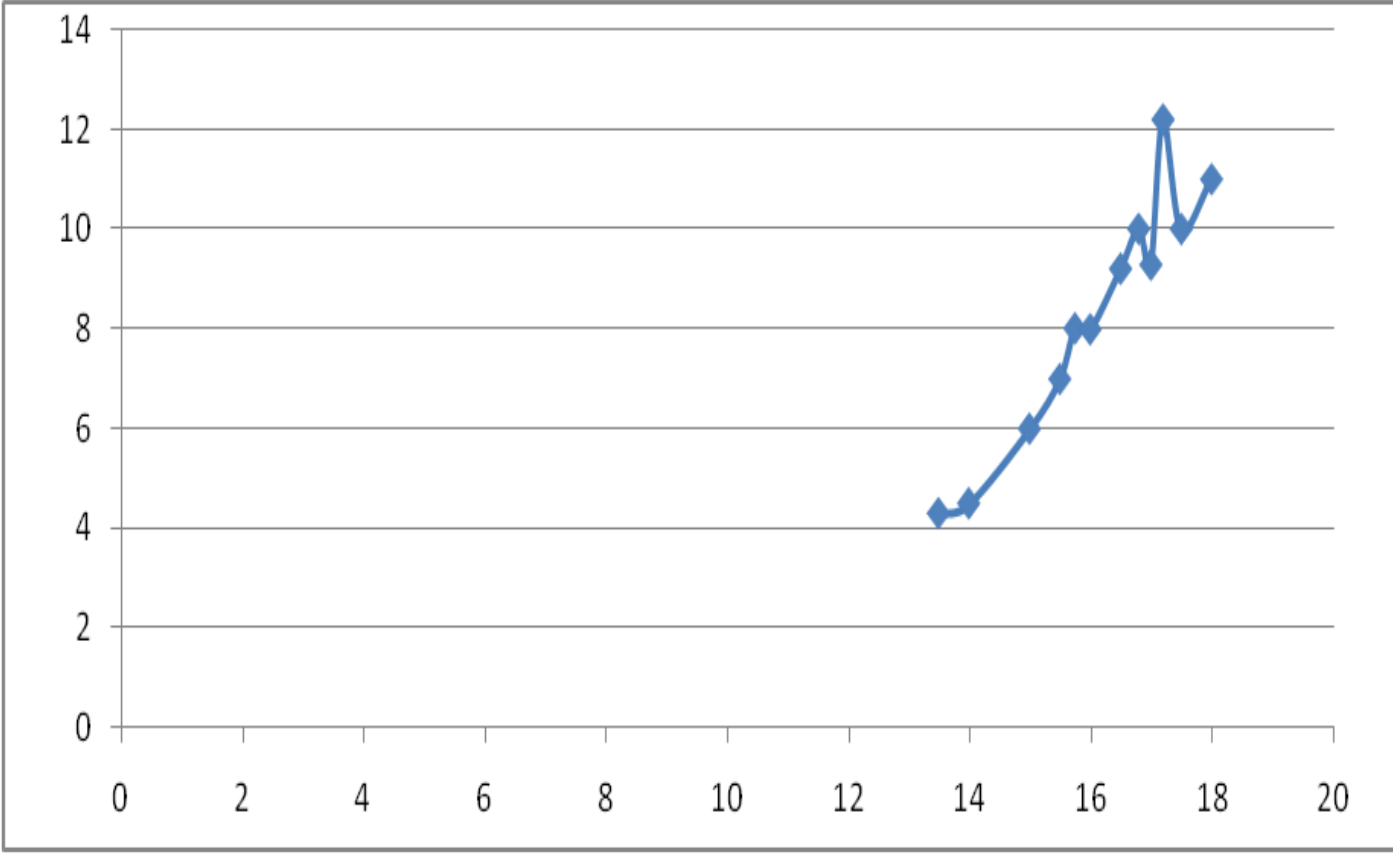

Figure 9 Load versus HCWCC

Step2. Generation of mathematical equations with the help of Figures (5) and (6) obtained equations for reduced $\mathrm{CO}$ and $\mathrm{HC}$ are,

$$
\text { COWCC }=0.093 C O^{3}-0.115 C O^{2}+0.27 C O-.167
$$


Step3. Modeling of equation 9 and 10 in MATLAB Simulink:

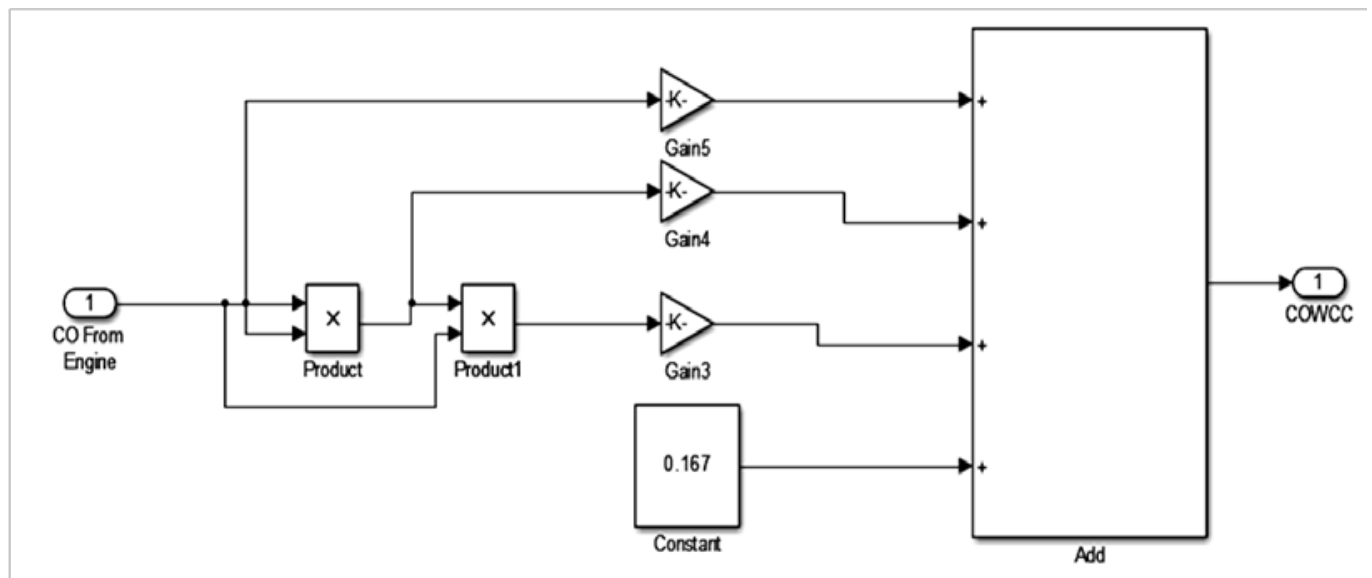

Figure 10. Simulation Model for COWCC

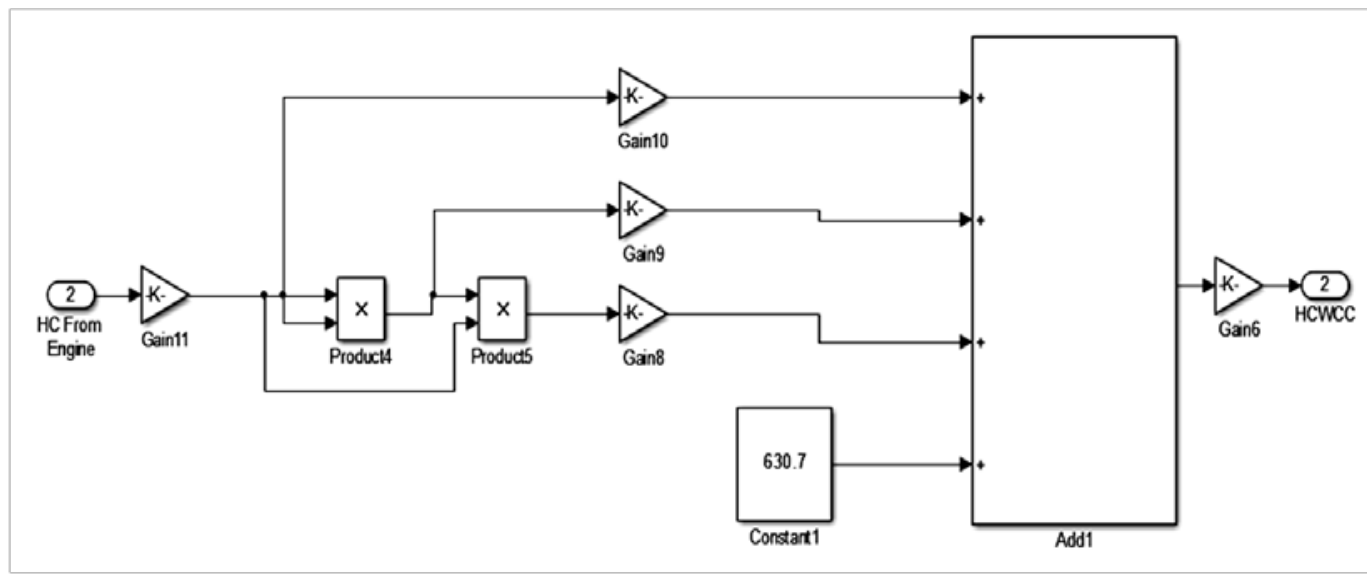

Figure 11. Simulation Model for HCWCC

Step4. Development of complete Catalytic Convertor model including the two in same model:

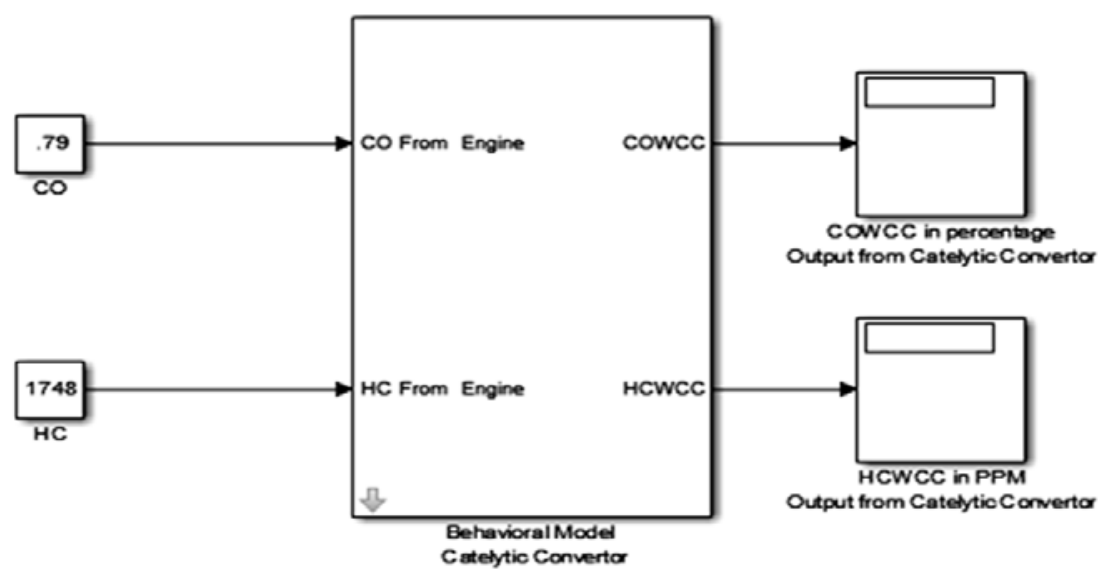

Figure 12. Simulation Model of Catalytic Convertor 


\subsection{Simulation of Complete system and simulation Results}

The complete simulation model for this paper has been successfully implemented and shown in Figure (13).

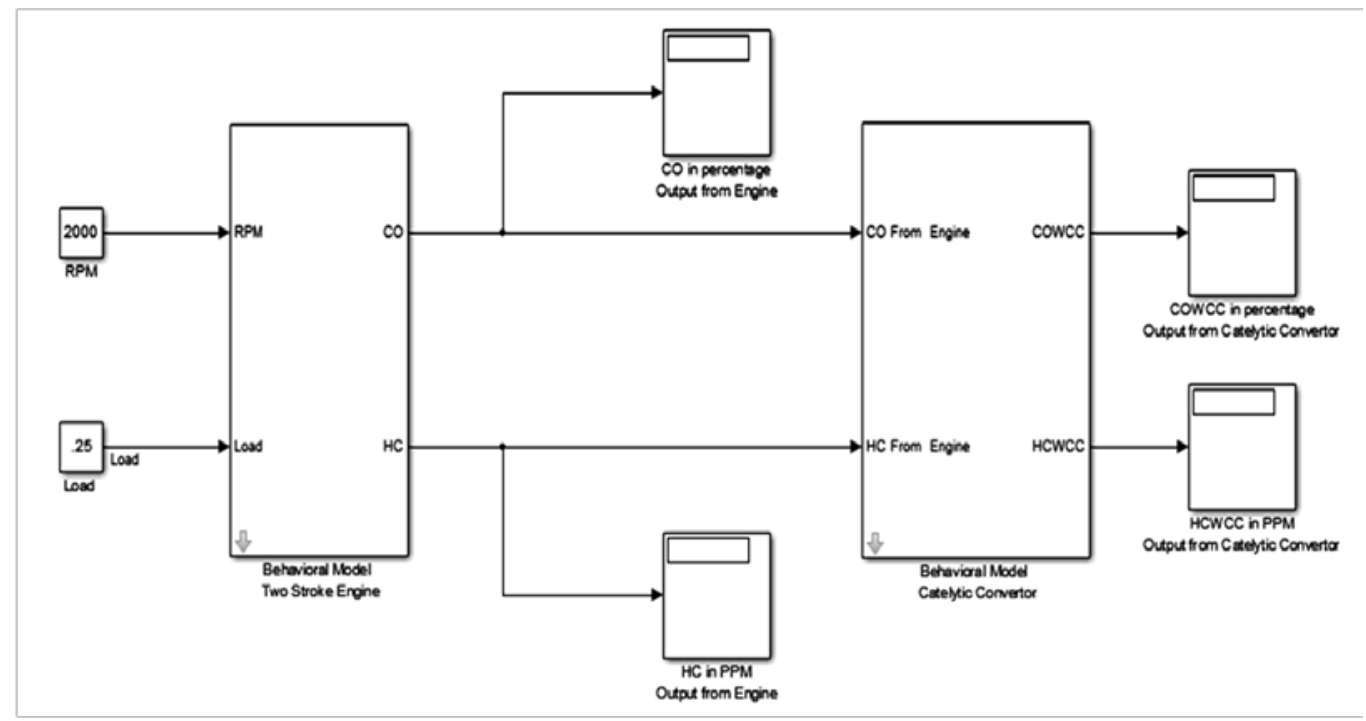

Figure 13. Simulation Model of Two Stroke Engine with Catalytic Converter

\subsection{Analysis of Developed Simulation Model}

After development of simulation model for a physical device, it must undergo for testing. This subsection provides a complete statistical analysis for practical engine with catalytic convertor and simulation model developed. To present a deep analysis, the complete analysis is divided in two parts. In first part we have shown analysis of engine model alone, while in second part an analysis of complete engine with catalytic convertor as shown is briefly discussed.

\subsubsection{Analysis of Engine Alone}

For the proper analysis of developed engine model, comparative evaluated values for the two stroke engine are shown in Table (5).

Table 5

\begin{tabular}{|c|c|c|l|l|l|l|l|}
\hline \multirow{3}{*}{$\begin{array}{c}\text { Speed } \\
\text { In RPM }\end{array}$} & \multirow{3}{*}{ Load } & \multicolumn{2}{|c|}{ CO in \% } & \multicolumn{2}{c|}{ HC in PPM } \\
\cline { 3 - 8 } & & Practical & Simulation & $\begin{array}{l}\text { Percentage } \\
\text { Error }\end{array}$ & Practical & Simulation & $\begin{array}{l}\text { Percentage } \\
\text { Error }\end{array}$ \\
\hline \multirow{5}{*}{1500} & 0.25 & 1.5 & 1.49 & $0.66 \%$ & 1750 & 1748 & $0.114 \%$ \\
\cline { 2 - 8 } & 0.5 & 1.2 & 1.19 & $0.83 \%$ & 1650 & 1648 & $0.121 \%$ \\
\cline { 2 - 8 } & 0.75 & 1.3 & 1.29 & $0.76 \%$ & 1700 & 1698 & $0.117 \%$ \\
\cline { 2 - 8 } & 1 & 1.6 & 1.59 & $0.62 \%$ & 1800 & 1798 & $0.111 \%$ \\
\hline
\end{tabular}




\begin{tabular}{|c|c|c|c|c|c|c|c|}
\hline \multirow{4}{*}{1800} & 0.25 & 1.2 & 1.19 & $0.83 \%$ & 1600 & 1598 & $0.125 \%$ \\
\hline & 0.5 & 1 & 0.99 & $1.00 \%$ & 1550 & 1548 & $0.129 \%$ \\
\hline & 0.75 & 1.1 & 1.09 & $0.90 \%$ & 1575 & 1573 & $0.126 \%$ \\
\hline & 1 & 1.3 & 1.29 & $0.76 \%$ & 1700 & 1698 & $0.117 \%$ \\
\hline \multirow{4}{*}{2000} & 0.25 & 1.16 & 1.15 & $0.86 \%$ & 1500 & 1498 & $0.133 \%$ \\
\hline & 0.5 & 0.8 & 0.79 & $1.25 \%$ & 1350 & 1348 & $0.148 \%$ \\
\hline & 0.75 & 0.9 & 0.89 & $1.11 \%$ & 1400 & 1398 & $0.142 \%$ \\
\hline & 1 & 1.2 & 1.19 & $0.83 \%$ & 1600 & 1598 & $0.125 \%$ \\
\hline \multirow{4}{*}{2200} & 0.25 & 1.6 & 1.69 & $0.62 \%$ & 1800 & 1798 & $0.111 \%$ \\
\hline & 0.5 & 1.4 & 1.39 & $0.71 \%$ & 1600 & 1598 & $0.125 \%$ \\
\hline & 0.75 & 1.5 & 1.49 & $0.66 \%$ & 1680 & 1650 & $0.119 \%$ \\
\hline & 1 & 1.6 & 1.59 & $0.62 \%$ & 1720 & 1718 & $0.116 \%$ \\
\hline
\end{tabular}

From Table (5) it is clearly observable, that the maximum percentage error obtained for CO is $.25 \%$ and for HC is $0.148 \%$, which are very small and hence the developed behavioral simulation model of two stroke engine is the exact replica of practical two stroke engine considered for this work.

\subsubsection{Analysis of Complete Engine with Catalytic Convertor}

For the proper analysis of developed Catalytic Convertor model, comparative evaluated values for the Catalytic Convertor are shown in Table (6).

Table 6

\begin{tabular}{|c|c|c|c|c|c|c|c|}
\hline \multirow{2}{*}{$\begin{array}{l}\text { Speed } \\
\text { In RPM }\end{array}$} & \multirow[t]{2}{*}{ Load } & \multicolumn{3}{|c|}{ COWCC in \% } & \multicolumn{3}{|c|}{ HCWCC in PPM } \\
\hline & & Practical & Simulation & $\begin{array}{l}\text { Percentage } \\
\text { Error } \\
\text { (in \%) } \\
\end{array}$ & Practical & Simulation & $\begin{array}{l}\text { Percentage } \\
\text { Error } \\
\text { (in \%) } \\
\end{array}$ \\
\hline \multirow{4}{*}{1500} & 0.25 & 0.64 & 0.63 & 1.29 & 1200 & 1179.6 & 1.70 \\
\hline & 0.5 & 0.5 & 0.49 & 2.78 & 1080 & 1022.46 & 5.33 \\
\hline & 0.75 & 0.55 & 0.53 & 4.00 & 1150 & 1117.1 & 2.86 \\
\hline & 1 & 0.7 & 0.69 & 2.07 & 1250 & 1197.21 & 4.22 \\
\hline \multirow{4}{*}{1800} & 0.25 & 0.5 & 0.49 & 2.78 & 980 & 908.43 & 7.30 \\
\hline & 0.5 & 0.43 & 0.42 & 3.49 & 800 & 787.76 & 1.53 \\
\hline & 0.75 & 0.48 & 0.45 & 6.54 & 900 & 848.12 & 5.76 \\
\hline & 1 & 0.58 & 0.53 & 8.93 & 1148 & 1117.1 & 2.69 \\
\hline 2000 & 0.25 & 0.48 & 0.47 & 1.96 & 710 & 673.19 & 5.18 \\
\hline
\end{tabular}




\begin{tabular}{|c|c|c|c|c|c|c|c|}
\hline \multicolumn{1}{|c|}{} & 0.5 & 0.38 & 0.36 & 6.05 & 520 & 493.67 & 5.06 \\
\cline { 2 - 8 } & 0.75 & 0.4 & 0.38 & 3.85 & 700 & 650.4 & 7.09 \\
\hline \multirow{7}{*}{2200} & 0.5 & 0.49 & 2.78 & 850 & 820.43 & 3.48 \\
\hline & 0.25 & 0.7 & 0.69 & 2.07 & 1300 & 1197.21 & 7.91 \\
\cline { 2 - 9 } & 0.5 & 0.6 & 0.57 & 4.20 & 1000 & 908.43 & 9.16 \\
\hline & 0.75 & 0.65 & 0.63 & 3.52 & 1100 & 1026.7 & 6.66 \\
\hline
\end{tabular}

From Table (6) it is clearly observable, that the maximum percentage error obtained for $\mathrm{CO}$ is $8.93 \%$ and for $\mathrm{HC}$ is $9.16 \%$, which are very small and hence the developed behavioral simulation model of complete engine with catalytic convertor is the exact replica of practical complete two stroke engine with catalytic convertor considered for this work.

\section{Results and Discussion}

There are two methods of control of pollution namely; pre-pollution control and post pollution control. Many environmentalists are interested in using precious metal nanoparticles as exhaust filters, both for vehicles and for power plants. In vehicles, particularly those that are diesel-powered, the nano-particles have been shown to be effective in oxidizing harmful hydrocarbon compounds that are released in their exhaust, thereby reducing their negative impact on the atmosphere. Platinum, gold and palladium are the most commonly used when it comes to diesel filtering. The proposed method is very effective in the prevention of environmental pollution contributed from two-wheeler automobiles. It involves the use of copper nano-particle which is cheaper than the platinum, palladium and rhodium nano-particles used in automobiles. The catalyst increases the rate of reaction by adsorption of reactants in such a form that the activation energy for reaction is reduced far below its value in non-catalytic reaction. Copper metal is selected for the present work as it is cheaper than platinum, palladium and rhodium also it adsorbs the reactants molecule strongly enough to hold and active the reactants but not so strongly that the product can't breakaway also the diffusion of reactants and products into and out of the pore structure of copper took place efficiently. Due to this, the pollution level for the exhaust emission of S.I. engine has found to be reduced which is better with nano-sized catalytic converter.

The idea behind the work is to create a structure that exposes the maximum surface area of catalyst to exhaust stream, also minimizing the amount of catalyst required. Air pollution can be remediated using nanotechnology in several ways. One is through the use of nano-catalysts with increased surface area for gaseous reactions. Catalysts work by speeding up chemical reactions that transform harmful vapors from cars and industrial plants into harmless gases. To achieve this objective, an innovative design of catalytic converter for two-wheeler automobiles is proposed using nano-particle as a catalyst. The converter uses two different types of catalyst, reduction and oxidation catalyst. In the present work, the experimentation has been done for a two stroke engine with and without catalytic converter and the results clearly reveals that the emission level can be reduced by the use of catalytic converter. 


\section{Conclusion}

In the current scenario, the pollution control is a crucial area for research and development. Lots of work has been done by the researchers in this connection but the area is still lacking for an efficient technique which can provide highly robust emission control for all the operating conditions of vehicles. The idea behind the work is to create a structure that exposes the maximum surface area of catalyst to exhaust stream, also minimizing the amount of catalyst required. The exhaust gases pass through a bed of catalyst and the catalytic action takes place at surface of copper which are porous and the higher catalytic activity towards the oxidation of $\mathrm{CO}$ and $\mathrm{HC}$ could be due to the higher catalytic surface area of small nanoparticles.

The proposed method is very effective in the prevention of environmental pollution contributed from two-wheeler automobiles. It involves the use of copper nano-particle which is cheaper than the platinum, palladium and rhodium nano-particles used in automobiles. This paper opens a gateway to study the changes in the concentration of exhaust emissions due to the nano-material copper coating. The modeling will help in understanding the mathematical nature of the process and simulation will help in predicting the results with ease.

\section{Nomenclature:}

CO - Carbon Monoxide

CC - Catalytic Converter

HC - Hydrocarbon

COWCC - CO emission in \% with catalytic converter

COWOCC - CO emission in \% without catalytic converter

HCWCC - HC emission in PPM with catalytic converter

HCWOCC - HC emission in PPM without catalytic converter

$\mathrm{x}$ - Load

\section{References}

[1] P. S. Gilmour, A. Ziesenis, E. R. Morrison, M. A. Vickers, E. M. Drost and I. Ford, “Toxicological Applications Pharmacology, vol. 195, (2004), pp. 35-44.

[2] M. V. Twigg, "Roles of catalytic oxidation in control of vehicle exhaust emissions", J. Catalysis Today, vol. 117, no. 4, (2006), pp. 407-418.

[3] K. Kishore and M. V. S. Krishna, Journal of Scientific and Industrial Research, vol. 67, (2008), pp. 543-548.

[4] M. Thakur and N. K. Saikhedkar, International Science Congress, Haridwar, (2012) December 8-9.

[5] T. Mukesh and N. K. Saikhedkar, International Journal of Engineering Research and Applications, vol. 2, no. 5, (2012), pp. 1947-1952.

[6] D. L. Feldheim and C. A. Foss, "Metal Nano-particles: Synthesis, Characterization and Applications", Appl. Phys. A Mater. Sci. Process, vol. 78, (2004), pp. 73-79.

[7] A. K. Schaper, H. Hou, A. Greiner, R. Schneider and F. Philips, “One Pot Synthesis of Copper Nanoparticles at Room Temperature and its Catalytic Activity”, Appl. Phys. A Mater. Sci. Process, vol. 78, (2004), pp. 8599.

[8] T. Mukesh and N. K. Saikhedkar, Abhinav Journal, vol. 1, no. 11, (2012), pp. 32-38.

[9] M. V. S. Murali Krishna, K. Kishor, P. V. K. Murthy, A. V. S. S. K. S. Gupta, S. Narsimha Kumar, International Journal of Scientific and Technology Research, vol. 1, no. 2, (2012), pp. 85-90.

[10] T. Mukesh, S. Shilpa and N. K. Saikhedkar, Abhinav Journal, vol. 3, no. 1, (2012), pp. 1-10. 
[11] C. M. Silva, M. Costa, T. L. Farias and H. Santos, “Energy Conversion and Management”, vol. 47, (2008), pp. 2281-2282.

[12] M. V. S. Murali Krishna and K. Kishor, "Performance of Copper Coated Spark Ignition Engine with Methanol Blended Gasoline with Catalytic Converter”, International Journal of Scientific and Technology Research, vol. 67, (2008), pp. 543-548.

[13] M. Samim, M. K. Kaushik and A. Maitra, Mater. Sci., vol. 30, no. 5, (2007), pp. 535-540.

[14] A. Durairajan, T. Kavita, A. Rajendran and L. A. Kumarswamidas, Indian J. Innovations Dev., vol. 1, no. 5, (2012), pp. 315-319.

[15] S. Prabhu and B. K. Vinayagam, International Journal of Nanotechnology and Applications, vol. 3, no. 1, (2009), pp. 17-28.

[16] M. S. Shehata and Razak, Engineering Research Journal, vol. 120, (2008), pp. M33-M57.

[17] T. Mukesh and N. K. Saikhedkar, "Control of Exhaust Emissions and Enhancement of Retention Time for Four Stroke Engine Using Nano-sized Copper Metal Spray”, International Journal of Scientific \& Engineering Research, vol. 4, no. 2, (2012), pp. 1-9.

\section{Authors}

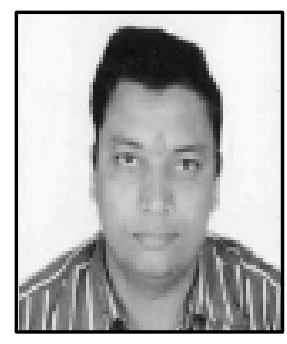

Mukesh Thakur is a Research Scholar from Dr. C.V. Raman University, Bilaspur. He is also working as a Reader in the Department of Mechanical Engineering of Rungta College of Engineering and Technology, Raipur. He has published his research papers in many national and international conferences and journals. He is also a life member of the Indian Science Congress Association and the Indian Society for Technical Education. He has won many awards for excellent teaching during his academic tenure and is like by one and all. He has also guided many undergraduate students in their project work.

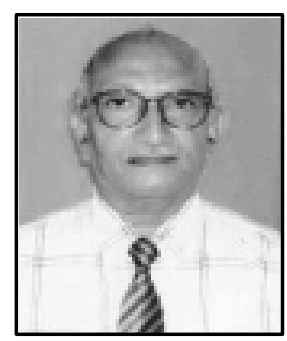

Co-Author's Name: N. K. Saikhedkar is presently working as a Director and professor in the department of Mechanical Engineering of Raipur Institute of Technology, Raipur. He has done his $\mathrm{PhD}$ in thermal engineering from IIT, Bombay. He has published his research papers in many national and international conferences and journals. He is also a life member of many national and international associations. He has vast experience in teaching and is considered as an ideal by many. 